\title{
An audit of pain management following pediatric day surgery at British Columbia Children's Hospital
}

\author{
Serena Shum BHk${ }^{1}$, Joanne Lim MASc ${ }^{2,3}$, Trish Page RN${ }^{4}$, Elizabeth Lamb RGN RSCN BMedSci ${ }^{5}$, Jennifer Gow PhD ${ }^{2,3}$, \\ J Mark Ansermino MB BCh MMed MSc FFA FRCPC ${ }^{2,3}$, Gillian Lauder MB BCh FRCA FRCPC 3,6
}

\begin{abstract}
S Shum, J Lim, T Page, et al. An audit of pain management following pediatric day surgery at British Columbia Children's Hospital. Pain Res Manage 2012;17(5):328-334.

A prospective audit of 225 children was conducted to evaluate current pain management strategies both in-hospital and at home following day surgery at British Columbia Children's Hospital (Vancouver, British Columbia). Anesthetic, postanesthetic care unit and surgical day care unit records were collected to generate in-hospital data. A telephone questionnaire was administered $48 \mathrm{~h}$ postdischarge for at home data. Pain reports and scores were significantly higher $(\mathrm{P}<0.01)$ at home compared with in-hospital. Children undergoing certain procedures were more likely to experience significant pain. Although good pain control was commonly achieved after surgery, improvements may be possible by increasing the use of multimodal analgesia, providing standardized written discharge instructions and using surgery-specific pediatric analgesia guidelines.
\end{abstract}

Key Words: Children; Day surgery; Parents; Pediatric anesthesia; Postoperative pain assessment; Postoperative pain management

E ective pediatric day surgery offers several benefits to children and their families over inpatient surgery. These include reduced psychological distress, less disruption to family routine and a decreased risk of hospital-acquired infections (1). Day surgery is also associated with reduced health care costs (2). However, it is not without disadvantages. In particular, postoperative pain assessment and management is complicated by devolving responsibility to parents/caregivers.

Pain relief is considered a basic human right (3), and the Joint Commission on Accreditation of Healthcare Organizations has instituted recommendations to attempt to achieve this goal in hospitals (4). Good pain control is imperative during the postoperative period; good quality postoperative pain management can enhance functional recovery, improve long-term functional outcomes (5), and improve child and family satisfaction (6). In contrast, poor postoperative pain control can increase postoperative morbidity, such as poor oral fluid intake, sleep disturbance, behavioural changes and vomiting (7).

Following day surgery, the child's parents/caregivers need the knowledge, assessment skills and confidence to manage their child's pain effectively. However, evidence exists that parent/caregivers tend to administer insufficient doses of analgesia after day surgery even when significant pain is recognized (8-10). One recent study revealed that parents provided a median of only a single dose of analgesic medications (range 0 to 3 ) during the first $48 \mathrm{~h}$ after day surgery despite recognizing significant pain in their children (11). Several factors may contribute to this parental hesitation to administer appropriate analgesic medications following pediatric day surgery. Obstacles to effective pain management postoperatively include misconceptions such as belief that it is preferable to limit the amount of analgesic medication given to children, belief that the less often analgesic medications are used, the more effective they are $(8,10-12)$, and belief that the use of
La vérification de la prise en charge de la douleur après des chirurgies d'un jour en pédiatrie au British Columbia Children's Hospital

Les chercheurs ont procédé à la vérification prospective de 225 enfants afin d'évaluer les stratégies courantes de prise en charge de la douleur en milieu hospitalier et à la maison après une chirurgie d'un jour au British Columbia Children's Hospital de Vancouver, en Colombie-Britannique. Ils ont colligé les dossiers de l'unité de soins anesthésiques et postanesthésiques et de l'unité de chirurgie d'un jour pour obtenir des données hospitalières et ont fait subir un questionnaire téléphonique 48 heures après le congé pour obtenir des données à la maison. Les déclarations et indices de douleur étaient considérablement plus élevés $(\mathrm{P}<0,01)$ à la maison qu'à l'hôpital. Les enfants qui subissaient certaines interventions étaient plus susceptibles de ressentir une douleur marquée. Même si on parvenait souvent à un bon contrôle de la douleur après l'opération, il serait peut-être possible de l'améliorer en utilisant davantage l'analgésie multimodale, en remettant des directives écrites standardisées au congé et en recourant à des lignes directrices sur l'analgésie adaptées aux diverses opérations chez certains enfants.

analgesic medications predisposes their children to becoming addicted to such medications $(11,12)$. Other obstacles include ignorance about the risks and modes of action of analgesic medications $(8,13)$, concerns regarding adverse effects of analgesic medications $(8,10,11,13)$, inability to properly assess their child's pain (14), lack of adequate written instructions for pain management $(6,13,15)$, and lack of understanding of verbal or written instructions (8), which may be exacerbated by discrepancies in instructions provided by nurses and doctors (6), poor communication between nurses and parents, as well as health care providers' knowledge deficits (16).

The nature and amount of guidance provided by a nurse is affected by factors such as his/her age, education, and work and personal experiences (17). Nurses who are older, more educated and experienced, and have had two or more previous hospitalizations of their own children tend to be more active in providing information regarding pediatric pain relief to parents/caregivers than nurses who lack these characteristics (17).

To ensure effective pain management at British Columbia Children's Hospital (BCCH, Vancouver, British Columbia), we sought to determine parental/caregiver barriers to good pain relief for children undergoing day surgery at $\mathrm{BCCH}$. There are no recent $\mathrm{BCCH}$ audit data to evaluate the efficacy of existing pain management strategies during recovery at home. In addition, there are limited data published on pediatric pain control outcomes in this population. The aim of the present pain management audit was to determine the current status of pain relief at discharge and in the first $48 \mathrm{~h}$ at home following elective pediatric day surgery at $\mathrm{BCCH}$. The specific objectives of the present audit were to evaluate parental/caregiver perception of current $\mathrm{BCCH}$ institutional pain management information, to document family (parental) reports of pain within the first $48 \mathrm{~h}$ postdischarge, to evaluate

${ }^{1}$ Queen's University; ${ }^{2}$ Department of Anesthesia, British Columbia Children's Hospital; ${ }^{3}$ Department of Anesthesiology, Pharmacology $\mathcal{F}^{2}$

Therapeutics, University of British Columbia; ${ }^{4}$ Surgical Daycare Unit, British Columbia Children's Hospital; ${ }^{5}$ Post-Anesthetic Recovery Unit,

British Columbia Children's Hospital; ${ }^{\circ}$ Acute Pain Service, British Columbia Children's Hospital

Correspondence: Dr Gillian Lauder, Department of Anesthesia, British Columbia Children's Hospital, 1L7 - 4480 Oak Street,

Vancouver, British Columbia, V6H 3V4. Telephone 604-875-2711, fax 604-875-3221, e-mail glauder@cw.bc.ca 
adequacy of current pain management strategies, to assess parental/ caregiver satisfaction and confidence with current $\mathrm{BCCH}$ institutional pain management protocols for discharge from day surgery, and, if necessary, to formulate recommendations to improve pain management strategies following day surgery at $\mathrm{BCCH}$ based on the results of the present audit.

\section{METHODS}

The present study was approved by and conducted in accordance with the guidelines of the University of British Columbia/Children's and Women's Health Centre of British Columbia Research Ethics Board. A prospective audit of children undergoing elective day surgery from May 25, 2010 to July 9, 2010 was undertaken. A purposive, nonconsecutive sample of parents/caregivers of children younger than 18 years of age who underwent day surgery at $\mathrm{BCCH}$ was recruited. Consecutive recruitment of families (or weekend and holiday recruitment) was not possible due to resource limitations; the sole research assistant assigned to this project could not simultaneously collect data from the different perioperative locations in the hospital. An attempt to capture diverse types of day surgery procedures was made by recruiting children receiving different types of surgeries. Subjects were not recruited if they were unable to read or understand English. Nonsurgical procedures, such as magnetic resonance imaging or other noninvasive radiological procedures, or planned admission were also exclusion criteria for the present audit.

After obtaining informed consent, in-hospital data were collected from the anesthetic, postanesthetic care unit (PACU), and surgical day care unit (SDCU) records. Because this was an audit of quality of pain control, only data that were part of the established practice in the routine monitoring and assessment of children admitted to the PACU and SDCU were collected. The following data were collected: child demographics (birth date, weight), date and type of procedure, preoperative data (premedication received), intraoperative data (analgesic medications received, local anesthetic technique received) and postoperative data. Postoperative data collected included nurse supplied PACU pain ratings (on admission, on regaining consciousness, on receipt of analgesia, at discharge and analgesic medications received); nurse supplied SDCU pain ratings (on admission, on regaining consciousness, on receipt of analgesia, at discharge and analgesic medications received); and a telephone follow-up $48 \mathrm{~h}$ postdischarge, following a scripted questionnaire (Appendix 1).

In the PACU, a pain score was generated using the face, legs, activity, cry, consolability (FLACC) scale (18) or the visual analogue scale (VAS) (19). The FLACC scale is validated for use in children two months to seven years of age in the PACU (18). The VAS scale is a validated visual self-report of pain (19). SDCU nurses evaluated pain levels for each child using the same scale that was used in the PACU for that child.

Parents/caregivers were contacted $48 \mathrm{~h}$ postdischarge and administered a 15-variable, partially-validated, structured questionnaire (Appendix 1). The questionnaire consisted of six domains:

1. Type of pain management information received at discharge (ie, written or verbal).

2. Parental assessment of pain levels experienced by the child on discharge and during the first and second $24 \mathrm{~h}$ of home recovery.

3. Objective pain assessment (14).

4. Types of analgesic medications administered at home and frequency of use.

5. Confidence with managing child's pain at home and perceived adequacy of discharge instructions received, measured on a fivepoint Likert scale ( 1 being not at all confident to 5 being very confident).

6. Satisfaction with child's pain management in-hospital and following discharge on a five-point Likert scale ( 1 being very dissatisfied to 5 being very satisfied).
TABLE 1 Number of subjects captured, grouped according to
surgical specialty

\begin{tabular}{|c|c|c|c|}
\hline \multirow{2}{*}{$\begin{array}{l}\text { Surgical } \\
\text { specialty }\end{array}$} & \multirow[b]{2}{*}{ n (\%) } & \multicolumn{2}{|c|}{ Day cases } \\
\hline & & Total, $\mathbf{n}$ & Cases audited, \% \\
\hline Otolaryngology & $48(21)$ & 130 & 36.9 \\
\hline Ophthalmology & $43(19)$ & 123 & 35.0 \\
\hline Urology & $38(17)$ & 97 & 39.2 \\
\hline Dental & $34(15)$ & Unknown & Unknown \\
\hline Plastics & $20(9)$ & 68 & 29.4 \\
\hline Orthopedics & $19(9)$ & 91 & 20.9 \\
\hline General surgery & $13(6)$ & 79 & 16.5 \\
\hline Other* & $10(5)$ & NA & NA \\
\hline Total & $225(100)$ & NA & NA \\
\hline
\end{tabular}

*Other includes radiological interventions (neck needle biopsy, $n=1$ ), dermatological procedures (pulsed dye laser, $n=5$ ) and gastroenterological procedures (biopsies, $n=3$; biopsy with pyloric dilation, $n=1$ ). NA Not applicable

In addition, at the end of the structured interview, parents/caregivers were invited by the interviewer to comment on any aspect pertaining to the pain management received by their child either in-hospital or at home.

\section{Statistical analysis}

Descriptive statistics were performed using Microsoft Excel 2008, version 12.0 (Microsoft Corporation, USA). Data analysis was performed using StatsDirect Statistical Software, version 2.4.4 (StatsDirect Ltd, United Kingdom). The Kruskal-Wallis test (one-way ANOVA by ranks) was used to compare nominal (nonordered) and ordinal variables. In case of significant difference $(\mathrm{P}<0.01)$, all possible pairwise comparisons between groups were made using the Dwass-SteelCritchlow-Fligner method $(\alpha=0.01)$ (20). Spearman's rank correlation was used to identify relationships between ordinal variables. Results were deemed to be statistically significant at $\mathrm{P}<0.05$.

\section{RESULTS}

The audit was conducted over a six-week period. During this time, a total of 1003 children were admitted through the SDCU, of which 811 were planned for surgery and discharge on the same day. Two hundred fifty-two families consented to participate in the present audit. Of the 252 recruits, 23 were not contactable by telephone within $72 \mathrm{~h}$ of discharge and were excluded from the analysis. Of the remaining 227 subjects who completed the telephone questionnaire, two were parents/ caregivers of children with chronic pain. Because postoperative pain level was an outcome measure of the present audit, these children were excluded. This left 225 subjects for analysis. The mean age of the subjects was 5.5 years (range four months to 17 years), and the mean weight of the subjects was $25.3 \mathrm{~kg}$ (range $6.7 \mathrm{~kg}$ to $142.8 \mathrm{~kg}$ ). Fifty-two per cent $(n=117)$ of these children were between one and four years of age, inclusive, and they were recruited from across the spectrum of surgical specialties performed at $\mathrm{BCCH}$. An average of $29 \%$ (range $16.5 \%$ to $36.9 \%$ ) of day surgical cases admitted to any given surgical specialty were recruited to the present study (Table 1).

\section{Analgesic premedication}

The vast majority of children received one ( $\mathrm{n}=90$ [40.4\%]) or two $(n=134$ [59.6\%]) analgesic premedications. Four children did not receive any premedications and one child received three premedications. The most frequently used analgesic premedications were acetaminophen ( $\mathrm{n}=163$ [72.4\%]) and ibuprofen ( $\mathrm{n}=108$ [48.9\%]) (Table 2). All doses were given as prescribed and were within the acceptable range for weight.

\section{Intraoperative analgesia}

For intraoperative analgesia, 39 individuals (17.4\%) were given a short-acting opioid analgesia (ie, remifentanil), 127 (56.4\%) received 


\section{TABLE 2}

\section{Type of premedication(s)* received $(n=225)$}

\begin{tabular}{lc}
\hline Type & $\mathrm{n}(\%)$ \\
\hline Acetaminophen & $163(72.4)$ \\
Ibuprofen & $108(48.9)$ \\
Codeine & $6(2.7)$ \\
Morphine & $2(0.9)$ \\
Clonidine & $1(0.4)$ \\
Gabapentin & $1(0.4)$ \\
\hline
\end{tabular}

${ }^{*}$ Premedication is analgesia given before entering the operating room

TABLE 3

Analgesic medications administered in the postanesthetic care unit $(n=225)$

\begin{tabular}{lc}
\hline Medication & $\mathrm{n}(\%)$ \\
\hline Morphine & $39(17.3)$ \\
Acetaminophen & $13(5.8)$ \\
Fentanyl & $10(4.4)$ \\
Ketorolac & $9(4.0)$ \\
Codeine & $8(3.6)$ \\
Others: ibuprofen, diclofenac, Tylenol 3* & $4(1.8)$
\end{tabular}

*Johnson and Johnson, USA

\section{TABLE 4}

Type and frequency of analgesic medications given by parents/caregivers in the first and second $24 \mathrm{~h}$ postdischarge $(n=225)$

\begin{tabular}{|c|c|c|}
\hline \multirow[b]{2}{*}{$\begin{array}{l}\text { Analgesic } \\
\text { medications }\end{array}$} & \multicolumn{2}{|c|}{ Dose received } \\
\hline & $\begin{array}{c}\text { First } 24 \text { h } \\
\text { postdischarge, n (\%) }\end{array}$ & $\begin{array}{c}\text { Second } 24 \mathrm{~h} \\
\text { postdischarge, } \mathrm{n}(\%)\end{array}$ \\
\hline Acetaminophen only & $90(40.0)$ & $29(12.9)$ \\
\hline $\begin{array}{l}\text { Acetaminophen and } \\
\text { ibuprofen }\end{array}$ & $21(9.3)$ & $4(1.8)$ \\
\hline $\begin{array}{l}\text { Acetaminophen with } \\
\text { codeine }\end{array}$ & $45(20.0)$ & $15(6.7)$ \\
\hline Ibuprofen only & $4(1.8)$ & $6(2.7)$ \\
\hline $\begin{array}{l}\text { Ibuprofen, acetamino- } \\
\text { phen with codeine } \\
\text { and acetaminophen }\end{array}$ & $1(0.4)$ & $0(0.0)$ \\
\hline Naproxen & $1(0.4)$ & $1(0.4)$ \\
\hline $\begin{array}{l}\text { Naproxen and } \\
\text { acetaminophen with } \\
\text { codeine }\end{array}$ & $2(0.9)$ & $0(0.0)$ \\
\hline $\begin{array}{l}\text { Acetaminophen with } \\
\text { codeine and } \\
\text { ibuprofen }\end{array}$ & $7(3.1)$ & $1(0.4)$ \\
\hline Tramacet & $1(0.4)$ & $1(0.4)$ \\
\hline $\begin{array}{l}\text { Total that received } \\
\text { medication }\end{array}$ & $172(76.3)$ & $57(24.9)$ \\
\hline No medications & $53(23.7)$ & 168 (75.1) \\
\hline Total & $225(100)$ & $225(100)$ \\
\hline
\end{tabular}

fentanyl, $47(20.9 \%)$ received a nonsteroidal anti-inflammatory agent (NSAID) and 35 (15.6\%) received intravenous morphine. These systemic medications were supplemented with local anesthesia using infiltration $(n=96[80.7 \%])$, caudal $(n=18$ [15.1\%]) or nerve block $(n=13[10.9 \%])$. Of the 18 children who received single shot caudal anesthesia, 15 (83.3\%) underwent urological procedures. Of the 11 children who underwent circumcision, one $(9.0 \%)$ received caudal anesthesia, six $(54.5 \%)$ received a penile block and four (36.4\%) received neither. Of the nine children who underwent hypospadias repair, seven $(77.8 \%)$ received caudal anesthesia and
TABLE 5

Reported pain scores according to surgical day care unit nurses at discharge and by parents at $24 \mathrm{~h}$ and $48 \mathrm{~h}$ postdischarge $(n=225)$

\begin{tabular}{|c|c|c|c|}
\hline \multirow[b]{2}{*}{ Pain rating } & \multirow{2}{*}{$\begin{array}{l}\text { SDCU nurses } \\
\text { on discharge }\end{array}$} & \multicolumn{2}{|c|}{ Parents } \\
\hline & & at $24 \mathrm{~h}$ & at $48 \mathrm{~h}$ \\
\hline Pain free & $212(95.5)$ & 115 (51.1) & $159(70.7)$ \\
\hline Mild pain & $8(3.6)$ & $70(31.1)^{\star}$ & 44 (19.6) \\
\hline Significant pain & $0(0.0)$ & $39(17.3)^{*}$ & $20(8.9)$ \\
\hline Total, $\mathrm{n}$ & $220^{\dagger}$ & $224^{\dagger}$ & $223^{\dagger}$ \\
\hline
\end{tabular}

Data presented as $n(\%)$ unless otherwise indicated. ${ }^{*} P<0.01$ compared with pain rating on discharge (Kruskal-Wallis test). 'Excludes missing and 'not sure' responses. Percentages are calculated with $n=225$. SDCU Surgical day care unit

two $(22.2 \%)$ received a penile block. Both children who underwent dorsal slits had penile blocks. Orchidopexy was performed in eight children; four $(50.0 \%)$ of them received caudal anesthesia, one $(12.5 \%)$ received an ilioinguinal block and three $(37.8 \%)$ received neither.

Postoperative analgesia

Sixty-three patients (28\%) received at least one dose of analgesic medication in the PACU. Morphine was the most common analgesic medication used $(\mathrm{n}=39$ [17.3\%]) (Table 3). A mean of 2.3 (range 1 to 11) doses of analgesic medication were given in the PACU; the outlying 11 doses were topical tetracaine drops administered every 10 min. Seventy-four per cent $(n=167)$ of subjects had pain ratings of zero throughout their PACU stay. Acetaminophen was the most frequently used analgesic in the SDCU $(n=10[4.4 \%])$. Codeine $(n=7[3.1 \%])$ and morphine $(n=1[0.4 \%])$ were the other analgesic medications administered. Fourteen patients (6.2\%) received at least one dose of analgesic medication (mean 1.2, range 1 to 2 ) in the SDCU. Eighty-two per cent of children $(n=185)$ had pain ratings of zero throughout their SDCU stay.

Discharge instructions

Parents/caregivers were asked to recall the discharge instructions regarding analgesic medications. The majority $(n=166$ [73.7\%]) of parents/caregivers received verbal instructions for postdischarge pain management, while some $(n=39[17.3 \%])$ received written instructions and others $(n=20[9.0 \%])$ received no instructions for pain management. Eighty-six individuals $(38.2 \%)$ who received instruction reported that they were told to give analgesic medications at regular intervals regardless of the child's pain level, while 105 (46.7\%) reported that they were instructed to give analgesic medications as required.

Analgesic administration at home

The majority of parents/caregivers $(n=152$ [67.9\%]) adhered to instructions given by staff and administered the recommended analgesic medications. Eighty-one per cent $(n=183)$ of parents administered at least one dose of analgesic medication at home. The remaining 19\% $(n=42)$ did not receive any analgesic medications at home; none of these children experienced significant pain. A mean of 3.1 (range zero to 10 ) analgesic doses were administered during the first $24 \mathrm{~h}$ postdischarge, and a mean of 0.3 (range zero to four) were administered during the second $24 \mathrm{~h}$ period. Acetaminophen was by far the most common analgesic medication given by parents/caregivers at home, followed by its combination with either ibuprofen or codeine (Table 4).

Pain scores and predictors

Pain (mild, moderate or severe) was more likely to be reported by parents/caregivers when questioned at the $24 \mathrm{~h}$ telephone interview than reported by the SDCU nurses at the time of discharge $(T=17.5$, $\mathrm{P}<0.01$ ) (Table 5). All pairwise comparison among the three report groups, namely pain at discharge, pain during first $24 \mathrm{~h}$ postdischarge and pain during $48 \mathrm{~h}$ postdischarge, revealed that pain reported at $24 \mathrm{~h}$ 


\begin{tabular}{|c|c|c|c|c|c|c|c|c|}
\hline \multirow[b]{3}{*}{ Surgery type } & \multicolumn{4}{|c|}{ No/mild pain } & \multicolumn{4}{|c|}{ Significant pain } \\
\hline & \multicolumn{2}{|c|}{$24 \mathrm{~h}$} & \multicolumn{2}{|c|}{$48 \mathrm{~h}$} & \multicolumn{2}{|c|}{$24 \mathrm{~h}$} & \multicolumn{2}{|c|}{$48 \mathrm{~h}$} \\
\hline & $\mathbf{n}$ & $\begin{array}{l}\% \text { of cases of } \\
\text { surgery type }\end{array}$ & $\mathbf{n}$ & $\begin{array}{l}\% \text { of cases of } \\
\text { surgery type }\end{array}$ & $\mathbf{n}$ & $\begin{array}{l}\% \text { of cases of } \\
\text { surgery type }\end{array}$ & $\mathbf{n}$ & $\begin{array}{c}\% \text { of cases of } \\
\text { surgery type }\end{array}$ \\
\hline Other & 42 & 98 & 41 & 95 & 1 & 2 & 2 & 5 \\
\hline Ophthalmological & 38 & 88 & 40 & 93 & 5 & 12 & 3 & 7 \\
\hline Otolaryngological & 37 & 77 & 41 & 85 & 11 & 23 & 7 & 15 \\
\hline Dental & 29 & 85 & 32 & 94 & 5 & 15 & 2 & 6 \\
\hline Urological & 28 & 74 & 33 & 87 & 10 & 26 & 5 & 13 \\
\hline Orthopedic & 12 & 63 & 18 & 95 & 7 & 37 & 1 & 5 \\
\hline Total & 186 & 83 & 205 & 91 & 39 & 17 & 20 & 9 \\
\hline
\end{tabular}

after discharge was significantly different from pain at discharge $(\mathrm{P}=0.0002)$ and pain $48 \mathrm{~h}$ postdischarge $(\mathrm{P}<0.0001)$, whereas pain at discharge was not significantly different from pain $48 \mathrm{~h}$ postdischarge. Children with significant pain at $24 \mathrm{~h}$ postdischarge were most likely to have undergone orthopedic ( $n=7,36.8 \%$ of surgical type captured), otolaryngological ( $\mathrm{n}=11,22.9 \%$ of surgical type captured) or urological $(\mathrm{n}=10,35.7 \%$ of surgical type captured) procedures (Table 6). At $48 \mathrm{~h}$ postdischarge, children with significant pain were most likely to have undergone otolaryngological ( $\mathrm{n}=7,15 \%$ of surgical type captured) or urological ( $n=5,13 \%$ of surgical type captured) procedures (Table 6). Indeed, the surgical pain model was an important predictor of postdischarge pain for children: children undergoing otolaryngeal and orthopedic surgery were more likely to experience pain at $24 \mathrm{~h}$ (23\% and $37 \%$, respectively) and $48 \mathrm{~h}(15 \%$ and $13 \%$, respectively) postdischarge, and children undergoing urological surgery were more likely to experience significant pain at $24 \mathrm{~h}(26 \%)$ postdischarge compared with other day case surgical procedures. The parental/caregiver perception of their child's pain at discharge (reported when interviewed $48 \mathrm{~h}$ postdischarge) was also a predictor of postoperative pain, and there was a significant correlation (two-sided $\mathrm{P}<0.0001$ ) between this retrospective parental/caregiver pain rating at discharge and pain levels at $24 \mathrm{~h}$ and $48 \mathrm{~h}$ postdischarge. There were no other predictors of significant pain.

Parental/caregiver satisfaction and confidence with postoperative pain management

Mean ratings for parental/caregiver satisfaction with postoperative pain management in-hospital and at home were 4.8 and 4.7 , respectively, on a five-point Likert scale. The mean rating for parental/caregiver confidence with pain management during home recovery was 4.7. Parents/ caregivers generally felt well-informed by staff regarding analgesic medications, rating the adequacy of the information a mean of 4.7.

When parents/caregivers were asked to comment on areas for improvement in their child's experience of pain management following day surgery, the following recurring themes arose:

- No areas of improvement needed ( $\mathrm{n}=178$ [79.1\%])

- Need for written instructions ( $\mathrm{n}=8$ [3.6\%])

- Need analgesic medications for trip home from hospital $(n=5[2.2 \%])$

- Complaints about taste/colour of Tylenol Elixir (Johnson and Johnson, USA) ( $\mathrm{n}=5$ [2.2\%])

- Needed more, or clarification of, pain information ( $n=5$ [2.2\%])

- Would prefer stronger analgesic medications than the ones received $(n=4[1.8 \%])$

- Complaints regarding unrecognized or delayed response to pain while in hospital ( $n=3[1.3 \%])$

- Discrepancy in information received from different staff members $(n=2[0.9 \%])$

\section{DISCUSSION}

There were no reports of children experiencing significant (moderate or severe) pain on discharge from day surgery at $\mathrm{BCCH}$ by SDCU nurses, and the vast majority of children (90\%) experienced no or mild pain up to $48 \mathrm{~h}$ following discharge. However, some incidences of significant pain were reported within the $48 \mathrm{~h}$ postdischarge window by parents $(17 \%$ and $9 \%$ at $24 \mathrm{~h}$ and $48 \mathrm{~h}$, respectively). Indeed, pain scores at the time of discharge from hospital reported by parents/caregivers were higher than those reported by SDCU nurses.

The low to mild pain ratings by SDCU nurses at the time of discharge are interesting. The SDCU nurses will not discharge a child they believe to be in significant pain. However, when interviewed $48 \mathrm{~h}$ postdischarge, $9.0 \%(\mathrm{n}=20)$ of parents/caregivers believed their child did experience significant pain at discharge. Such discrepancies between discharge pain ratings from SDCU nurses and parents/ caregivers have been previously reported (21-23). In the present study, this retrospective parental/caregiver pain rating at discharge correlated significantly with postdischarge pain levels. It is unclear whether these parents/caregivers overestimated their child's pain or if they are just more attuned to their child's pain. The addition of a question of parental/caregiver perception of their child's pain to the discharge checklist, rather than a retrospective assessment, would not only help to clarify this but may also help to target children that may need alternative postdischarge analgesic medications.

\section{Multimodal analgesia}

As an institution, $\mathrm{BCCH}$ appears to be successful in achieving good pain control for day case surgery children during their time in the hospital through the adoption of multimodal analgesia. Multimodal analgesia is achieved through the combination of different analgesics that act by different mechanisms. It results in additive or synergistic analgesia that lowers the total doses of analgesics and incurs fewer side effects (24). Previous research has shown that the use of NSAIDs and opioid analgesics, with or without local anesthetic infiltration, leads to lower pain scores, the need for fewer analgesics and a prolonged time to requiring analgesics after surgery (25). In the present audit, multimodal analgesia included the use of systemic opioids, NSAIDs, wound infiltrations and blocks, where appropriate. Preventative medications were given diligently, with $98 \%$ of recruits receiving analgesic premedication. The majority $(88 \%)$ of subjects were also given analgesia intraoperatively. The most common intraoperative analgesic medication given was fentanyl, administered to more than one-half $(n=127[56.4 \%])$ of the sample.

Unfortunately, the multimodal approach is not maintained after the child leaves the hospital. The most common analgesic used at home was acetaminophen. One-half of the subjects relied solely on acetaminophen, while only one-fifth received ibuprofen. While acetaminophen is an efficacious medication, pain control may be improved through multimodal analgesia (26).

\section{Discharge instructions}

The majority of parents/caregivers were provided with verbal instructions at discharge. Most of these parents/caregivers recalled being told to give analgesic medications 'as needed'. Despite the lack of written instruction, parents/caregivers felt confident with and well informed 
about pain management at home. Furthermore, parents/caregivers in the present study administered more doses of analgesia within the first $48 \mathrm{~h}$ than previously reported (11). All patients in significant pain at home received regular medication. Despite this, the need for written instructions is apparent from the open-ended comments from parents/ caregivers. Specific written instructions for analgesic medications, preferably given before the day of surgery, would facilitate understanding and retention of verbal instructions (6) as well as standardize the content of instructions given to parents/caregivers.

Another barrier to effective pain control at home is the inability to properly assess a child's pain. While this was not a focus of the current study, it has been shown to be an issue in previous studies (27). Parents/caregivers can be educated regarding proper assessment techniques of their child's pain to decrease the probability that pain goes undetected at home.

\section{Surgery-specific pain outcomes}

Children undergoing otolaryngological, orthopedic and urological procedures were more likely to experience significant pain postdischarge compared with individuals undergoing other surgical procedures. While the orthopedic procedures varied in nature and complexity, tonsillectomy and adenoidectomy and hypospadias repair were the procedures most commonly associated with significant pain at $24 \mathrm{~h}$. However, the small sample size per individual surgical procedure precludes statistical evaluation of this association.

Most children receiving caudal anesthesia $(n=15$ [83.3\%]) and nerve blocks $(\mathrm{n}=13$ [92.3\%]) underwent urological procedures. However, in the present study, these procedures were more likely to result in significant pain at $24 \mathrm{~h}$ postdischarge than many other surgical procedures. This suggests that current local anesthetic techniques are inadequate. Given that the majority of patients were pain free at discharge from hospital, it would appear that these techniques provide analgesia for an insufficient period of time. It is clear that an evidence-based change in practice is required to maximize pain management when local anesthetic blocks wear off at home. Orthopedic and otolaryngological procedures were the other surgical types associated with higher incidences of significant postoperative pain. This finding is consistent with previous reports $(28,29)$ because both are inherently painful procedures.

The postoperative pain management of children at $\mathrm{BCCH}$ may benefit from the development of diagnosis-specific discharge instructions for the three types of surgeries (orthopedic, otolaryngological, and urological) that were more likely to produce significant pain postdischarge. Recent research has shown that diagnosis-specific discharge instructions can improve child satisfaction (30). A collaborative effort between surgeons, anesthesiologists, nursing staff and clinical pharmacists will be essential to producing such a surgery-specific, evidence-based guideline to optimize pain management at home following day surgery. Because the size of these subsets in the present audit was small, we are planning on performing another audit to target these particular procedures. The inclusion of a greater number of children will help identify the factors that lead to significant pain in these cases. Institution of measures to improve pain management (ie, parent/caregiver information leaflets and evidence-based, surgeryspecific, multimodal pain orders) will then be initiated and reaudited to close the audit cycle.

\section{Study limitations}

There were several limitations to the present study. First, a relatively small sample size precludes in-depth analysis of individual surgical procedures. Second, biases in sampling may have occurred, such as a nonconsecutive sample, and practice and parent/caregiver memory. Third, pain ratings were not obtained from children themselves and the accuracy of parents'/caregivers' evaluation of the child's pain may not accurately reflect the child's pain perception; this is an important consideration for future studies of this nature. Finally, a variety of surgical procedures were represented in the sample, all with different resultant postoperative pain levels.

\section{Recommendations}

Based on our results we recommend: first, an increased use of multimodal analgesia following discharge from hospital; second, the development of standardized written instructions for administration of analgesic medications and pain assessment by parents/caregivers; and finally, the development of surgery-specific evidence-based analgesia guidelines.

For increased robustness of future audits we recommend collecting data on a larger sample size. This would enable analysis of factors such as age, sex and confounding factors such as preoperative pain and anxiety.

\section{CONCLUSION}

The results of the present audit demonstrate that for the vast majority of children, BCCH staff and parents/caregivers are successful in achieving good pain control after day surgery. However, improvements can be made through the increased use of multimodal analgesia following discharge from hospital, and the development of standardized written instructions and surgery-specific, evidence-based analgesia guidelines.

\section{APPENDIX 1: 48 H SCRIPTED TELEPHONE QUESTIONNAIRE}

\section{INTRODUCTION}

Hello, this is (Name of Interviewer) calling on behalf of the Pediatric Anesthesia Research Team at BC Children's Hospital. May I please speak with (Name of Parent/Guardian)?

- If person is not there at the time, find out when to call back.

- If not correct person: when correct person answers repeat first paragraph and continue with the paragraph below.

- If the correct person is on the phone, continue.

Are you the best person to answer questions about the Day Surgery Care (Name of child) received?

- If best person is not there at the time, find out when to call back.

- If not best person, reintroduce when correct person answers and continue with the next section.

- If the best person is on the phone, continue.

\section{PURPOSE/CONSENT}

We are conducting a survey to determine the level of satisfaction with pain management after day surgery at BC Children's Hospital. This should take about 15 minutes. Your opinions are very important to us and we are interviewing only a select number of people.

Is this a good time to ask you some questions or would another time be better for you?

- If yes, continue with paragraph below.

- If not a good time, schedule a callback at a more suitable time and say 'Thank you for your time; I will call back at that time to speak to you'.

Do I have your permission to begin?

- If yes: Continue with paragraph below.

- If no: Terminate interview by saying: 'Thank you for your time. I apologize for any inconvenience. Goodbye'.

\section{Guarantee of anonymity/confidentiality}

Before we start, I'd like to assure you that this interview is confidential and completely voluntary. If we should come to any question which you do not want to answer, just let me know and we will go on to the next question. You may end this survey at any time. Whatever you decide, it will not change the health care you or your child usually receive.

Do you have any questions about the survey before we begin? Date_________ Time of Telephone Questionnaire: $\mathrm{h}$

SCRIPT: First, I would like to ask you for some basic identifying information. 
1. In your own words, what surgery did your child have? Answer format $=$ free text. If parent does not know the surgery, ask 'Who was your child's surgeon?'

2. What pain medication(s) was your child told to take? Answer format $=$ free text. The response 'do not know' is acceptable.

\section{DOMAIN \#1: Pain information}

SCRIPT: Thank you. Now I would like to ask you some questions regarding information you received about how to manage your child's pain.

1. In terms of managing pain after day surgery, did you receive...

$\square_{4}$ Written instructions from a nurse

$\square_{3}$ Verbal instructions from a nurse

$\square_{2}$ Written instructions from a doctor

$\square_{1}$ Verbal instructions from a doctor

$\square_{9}$ No information was received

$\square_{9}$ Not sure

2. What was that information?

$($ Answer format $=$ free text $)$

3. Did you seek out additional information after discharge on how to manage pain for your child?

(Answer format $=$ free text $)$

If so, how?

(Answer format $=$ free text. Code answer responses as internet, nurse helpline, surgeon, surgeon's office, friend, family, GP)

If yes to question [3], was this helpful?

(Answer format $=$ yes $/$ no, plus free text)

\section{DOMAIN \#2: Subjective pain assessment}

SCRIPT: Thank you. Now I would like to ask you some questions regarding any pain your child experienced after leaving the hospital.

1. Describe your child's pain at the time of discharge from the hospital:
$\square_{0}$ No pain
$\square_{1}$ Mild pain
$\square_{2}$ Moderate pain
$\square_{3}$ Severe pain
$\square_{4}$ Not sure

2. How long was your trip home?

3. Describe your child's pain on the trip home:

$\square_{0}$ No pain

$\square_{1}$ Mild pain

$\square_{2}$ Moderate pain

$\square_{3}$ Severe pain

$\square_{4}$ Not sure

4. Describe your child's pain at the moment (or at $48 \mathrm{~h}$ if contact was made after $48 \mathrm{~h}$ ):

$\square_{0}$ No pain

$\square_{1}$ Mild pain

$\square_{2}$ Moderate pain

$\square_{3}$ Severe pain

$\square_{4}$ Not sure

5. Describe your child's pain during the first $24 \mathrm{~h}$ after day surgery:

$\square_{0}$ No pain

$\square_{1}$ Mild pain

$\square_{2}$ Moderate pain

$\square_{3}$ Severe pain

$\square_{4}$ Not sure

6. What is the highest level of pain your child has experienced?

$\square_{0}$ No pain

$\square$ Mild pain

$\square_{2}$ Moderate pain

$\square_{3}$ Severe pain

$\square_{4}$ Not sure
DOMAIN \#3: Objective pain assessment

Since discharge from hospital has your child:

\begin{tabular}{|c|c|c|c|c|c|}
\hline & $\begin{array}{l}\text { Not } \\
\text { at all }\end{array}$ & $\begin{array}{c}\text { A } \\
\text { little }\end{array}$ & Somewhat & $\begin{array}{l}\text { Quite } \\
\text { a bit }\end{array}$ & $\begin{array}{l}\text { Not } \\
\text { sure }\end{array}$ \\
\hline $\begin{array}{l}\text { 1. Whined or complained more than } \\
\text { usual? }\end{array}$ & $\square_{1}$ & $\square_{2}$ & $\square_{3}$ & $\square_{4}$ & $\square_{5}$ \\
\hline 2. Cried more easily than usual? & $\square_{1}$ & $\square_{2}$ & $\square_{3}$ & $\square_{4}$ & $\square_{5}$ \\
\hline 3. Played less than usual? & $\square_{1}$ & $\square_{2}$ & $\square_{3}$ & $\square_{4}$ & $\square_{5}$ \\
\hline $\begin{array}{l}\text { 4. Not done the things s/he normally } \\
\text { does? }\end{array}$ & $\square_{1}$ & $\square_{2}$ & $\square_{3}$ & $\square_{4}$ & $\square_{5}$ \\
\hline 5. Acted more worried than usual? & $\square_{1}$ & $\square_{2}$ & $\square_{3}$ & $\square_{4}$ & $\square_{5}$ \\
\hline 6. Acted more quiet than usual? & $\square_{1}$ & $\square_{2}$ & $\square_{3}$ & $\square_{4}$ & $\square_{5}$ \\
\hline 7. Had less energy than usual? & $\square_{1}$ & $\square_{2}$ & $\square_{3}$ & $\square_{4}$ & $\square_{5}$ \\
\hline 8. Refused to eat? & $\square_{1}$ & $\square_{2}$ & $\square_{3}$ & $\square_{4}$ & $\square_{5}$ \\
\hline 9. Ate less than usual? & $\square_{1}$ & $\square_{2}$ & $\square_{3}$ & $\square_{4}$ & $\square_{5}$ \\
\hline 10. Held the sore part of his/her body? & $\square_{1}$ & $\square_{2}$ & $\square_{3}$ & $\square_{4}$ & $\square_{5}$ \\
\hline $\begin{array}{l}\text { 11. Tried not to bump the sore part of } \\
\text { his/her body? }\end{array}$ & $\square_{1}$ & $\square_{2}$ & $\square_{3}$ & $\square_{4}$ & $\square_{5}$ \\
\hline $\begin{array}{l}\text { 12. Groaned or moaned more than } \\
\text { usual? }\end{array}$ & $\square_{1}$ & $\square_{2}$ & $\square_{3}$ & $\square_{4}$ & $\square_{5}$ \\
\hline 13. Looked more flushed than usual? & $\square_{1}$ & $\square_{2}$ & $\square_{3}$ & $\square_{4}$ & $\square_{5}$ \\
\hline $\begin{array}{l}\text { 14. Wanted to be close to you more } \\
\text { than usual? }\end{array}$ & $\square_{1}$ & $\square_{2}$ & $\square_{3}$ & $\square_{4}$ & $\square_{5}$ \\
\hline $\begin{array}{l}\text { 15. Taken medication when s/he } \\
\text { normally refuses? }\end{array}$ & $\square_{1}$ & $\square_{2}$ & $\square_{3}$ & $\square_{4}$ & $a_{5}$ \\
\hline
\end{tabular}

DOMAIN \#4: Pain management

SCRIPT: Thank you. Now I would like to ask you some questions regarding how you managed your child's pain after leaving the hospital.

1. Have you given your child any pain relieving drugs: yes / no

If yes, please give details below: Please give details of medication, amount and medication effect. Note: Attempt to specify time; if unable, document frequency.

\begin{tabular}{|c|l|l|l|l|l|l|}
\hline $\begin{array}{c}\text { Drugs } \\
\text { Given }\end{array}$ & Name & Dose & Route & Time & Frequency & Effect \\
\hline 1. & & & & & & \\
\hline 2. & & & & & & \\
\hline 3. & & & & & & \\
\hline 4. & & & & & & \\
\hline 5. & & & & & & \\
\hline 6. & & & & & & \\
\hline 7. & & & & & & \\
\hline 8. & & & & & & \\
\hline
\end{tabular}

DOMAIN \#5: Confidence

SCRIPT: Thank you. Now I would like to ask you some questions regarding your confidence in managing your child's pain.

1. Did you feel comfortable asking the doctors at the hospital questions about pain management?

(Answer format $=$ yes $/$ no, plus free text)

2. Did you feel comfortable asking the nurses at the hospital questions about pain management?

(Answer format $=$ yes $/$ no, plus free text)

3. Did you have any questions about how to manage your child's pain before leaving hospital?

(Answer format = yes $/$ no, followed by free text of what the concerns are, if applicable.)

4. [If participant indicated that medication had been given]: Using a scale of 1 to 5 , where $1=$ not at all informed and $5=$ very informed, please indicate how well informed you felt about the medications prescribed for your child after his or her operation?

Very informed $\square_{5} \square_{4} \square_{3} \square_{2} \square_{1}$ Not at all informed 
5. Using a scale of 1 to 5 , where $1=$ not at all confident and $5=$ very confident, please indicate how confident you were managing your child's pain after his or her operation?

Very confident $\square_{5} \square_{4} \square_{3} \square_{2} \square_{1}$ Not at all confident

6. Describe how difficult it was to care for your child's pain at home following discharge:

Very difficult $\square_{5} \square_{4} \square_{3} \square_{2} \square_{1}$ Not at all difficult

If there was difficulty can you give details:

(Answer format $=$ free text $)$

7. In the future, if your child had surgery known to be associated with severe pain, would you feel comfortable giving your child morphine by mouth to manage pain at home, if it was deemed necessary by your physician?

Very comfortable $\square_{5} \square_{4} \square_{3} \square_{2} \square_{1}$ Very uncomfortable

(Plus free text)

\section{DOMAIN \#6: Satisfaction}

SCRIPT: Thank you. Now I would like to ask you some questions regarding how satisfied you are with how your child's pain was managed.

1. Will your child's pain management affect your decision to allow him/her to have day case surgery in the future?

(Answer format $=$ free text, if yes, please specify).

2. Using a scale of 1 to 5 , where $1=$ very dissatisfied and $5=$ very satisfied, please indicate how satisfied were you with how your child's pain was managed while at the hospital?

Very satisfied $\square_{5} \square_{4} \square_{3} \square_{2} \square_{1}$ Very dissatisfied

3. Using a scale of 1 to 5 , where $1=$ very dissatisfied and $5=$ very satisfied, please indicate how satisfied were you with how your child's pain was managed after leaving the hospital?

Very satisfied $\square_{5} \square_{4} \square_{3} \square_{2} \square_{1}$ Very dissatisfied

4. Using a scale of 1 to 5 , where $1=$ strongly disagree and $5=$ strongly agree, please indicate whether you agree or disagree with the following statements: If my child needed surgery again, I would want the pain treated in the same way.

Strongly agree $\square_{5} \square_{4} \square_{3} \square_{2} \square_{1}$ Strongly disagree

5. What do you think could be done to improve the quality of pain management your child received for his/her day case surgery?

(Answer format $=$ free text $)$

6. Do you have any comments that may help us in the future to manage pain in children following day case surgery?

$($ Answer format $=$ free text $)$

\section{REFERENCES}

1. Brennan LJ. Modern day-case anesthesia for children. Br J Anesth 1999;83:91-103.

2. Sadler GP, Richards H, Watkins G, Foster ME. Day case paediatric surgery: The only choice. Ann R Coll Surg 1992;74:130-3.

3. Brennan F, Carr DB, Cousins M. Pain management: A fundamental human right. Anesth Analg 2007;105:205-21.

4. Joint commission on accreditation of health care organizations and National Pharmaceutical Council, 2001.

http://www.jointcommission.org.

5. Morrison RS, Magaziner J, McLaughlin MA, et al. The impact of postoperative pain on outcomes following hip fracture. Pain 2003;103:303-11.

6. Kankkunen P, Vehvilainen-Julkunen K, Pietila AM, Halonen P. Is the sufficiency of discharge instructions related to children's postoperative pain at home after day surgery? Scand J Caring Sci 2003;17:365-72.
7. Sutters KA, Miaskowski C. Inadequate pain management and associated morbidity in children at home after tonsillectomy. J Pediatr Nurs 1997;12:178-85.

8. Finley GA, McGrath PJ, Forward SP, McNeill G, Fitzgerald P. Parents' management of children's pain following 'minor' surgery. Pain 1996;64:83-7.

9. Wilson ME, Helgadottir, HL. Patterns of pain and analgesic use in 3- to 7-year-old children after tonsillectomy. Pain Manag Nurs 2006; 7:159-66.

10. Hamers JPH, Abu-Saad HH. Children's pain at home following (adeno) tonsillectomy. European Journal of Pain 2002;6:213-9.

11. Rony RYZ, Fortier MA, Chorney JML, Perret D, Kain, ZN. Parental postoperative pain management: Attitudes, assessment, and management. Pediatrics 2010;125:e1372.

12. Gedaly-Duff V, Ziebarth D. Mothers' management of adenoidtonsillectomy pain in 4- to 8-year olds: A preliminary study. Pain 1994;57:293-9.

13. Kankkunen P, Vehvilainen-Julkunen K, Pietila AM, Kokki H, Halonen P. Parents' perceptions and use of analgesics at home after children's day surgery. Paediatr Anaesthes 2003:13;132-40.

14. Chambers CT, Reid GJ, McGrath PJ, Finley GA. Development and preliminary validation of a postoperative pain measure for parents. Pain 1996;68:307-13.

15. Jonas $\mathrm{D}$, Worsley-Cox K. Information giving can be painless. J Child Health Care 2000;4:55-8.

16. Simons J, Roberson E. Poor communication and knowledge deficits: Obstacles to effective management of children's postoperative pain. J Adv Nurs 2002;40:78-86.

17. Polkki T. Nurses' perceptions of parental guidance in pediatric surgical pain relief. Int J Nurs Stud 2002;39:319-27.

18. Merkel SI, Shayevitz JR, Voepel-Lewis T, Malviya S. The FLACC: A behavioral scale for scoring postoperative pain in young children. Pediatr Nurs 1997;23:293-7.

19. Scott J, Huskisson EC. Graphic representation of pain. Pain 1976;2:175-84

20. Critchlow DE, Fligner MA. On distribution-free multiple comparisons in the one-way analysis of variance. Commun Stat Theory Methods 1991;20:127-39.

21. Munro HM, Malviya S, Lauder GR, Voepel-Lewis T. Pain relief in children following out child surgery. J Clin Anesthes 1999;11:187-91.

22. Romsing J, Moller-Sonnergaard J, Hertel S, Rasmussen M. Postoperative pain in children: Comparison between ratings of children and nurses. J Pain Symptom Manage 1996;11:42-6.

23. Miller D. Comparisons of pain ratings from postoperative children, their mothers, and their nurses. Pediatr Nurs 1996;22:145-9.

24. Dahl JB, Kehlet H. Non-steroidal anti-inflammatory drugs: Rationale for use in severe postoperative pain. Br J Anaesth 1991;66:703-12.

25. Fengling J, Chung F. Multimodal analgesia for postoperative pain control. J Clin Anesthes 2001;13:524-39.

26. Pierce CA, Voss B. Efficacy and safety of ibuprofen and acetaminophen in children and adults: A meta-analysis and qualitative review. Ann Pharmacother 2010;44:489-506.

27. Chambers CT, Reid GJ, Craig, KD, McGrath PJ, Finley GA. Agreement between child and parent reports of pain. Clin J Pain $1998 ; 14: 336-42$.

28. Husband AD, Davis A. Pain after tonsillectomy. Clin Otolaryngol Allied Sci 1996;21:99-101.

29. McGrath B, Elgendy H, Chung F, Kamming D, Curti B, King S. Thirty percent of patients have moderate to severe pain $24 \mathrm{hr}$ after ambulatory surgery: A survey of 5,703 patients. Can J Anesth 2004;51:886-91.

30. Lo S, Stuenkel DL, Rodriguez L. The impact of diagnosis-specific discharge instructions on child satisfaction. J Perianesthes Nurs 2009;24:156-62. 


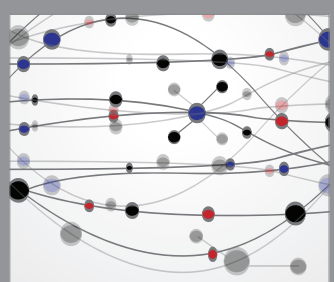

The Scientific World Journal
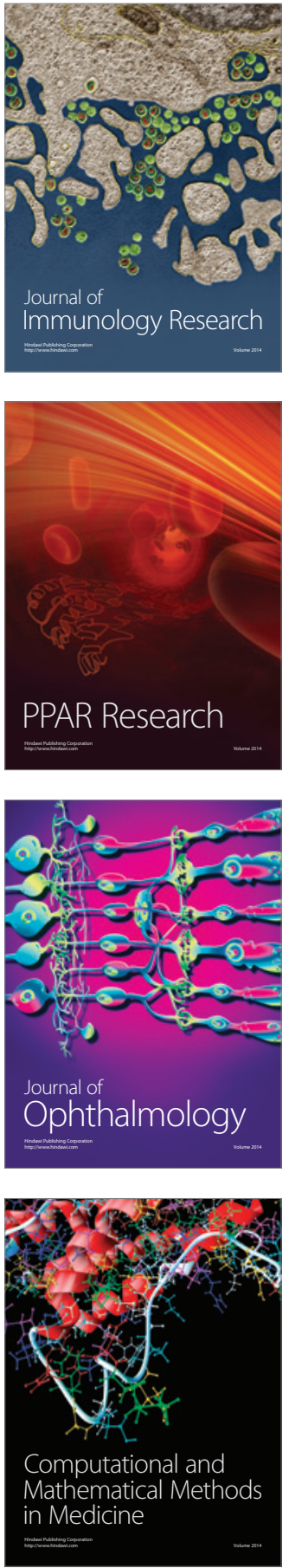

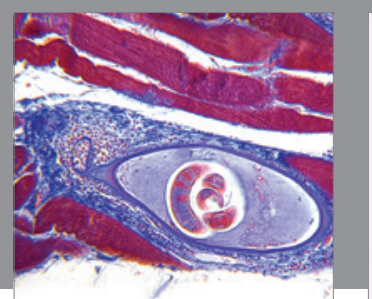

Gastroenterology Research and Practice

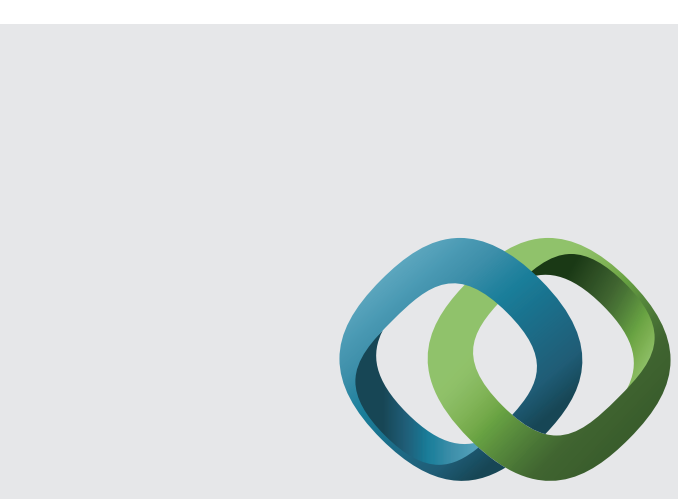

\section{Hindawi}

Submit your manuscripts at

http://www.hindawi.com
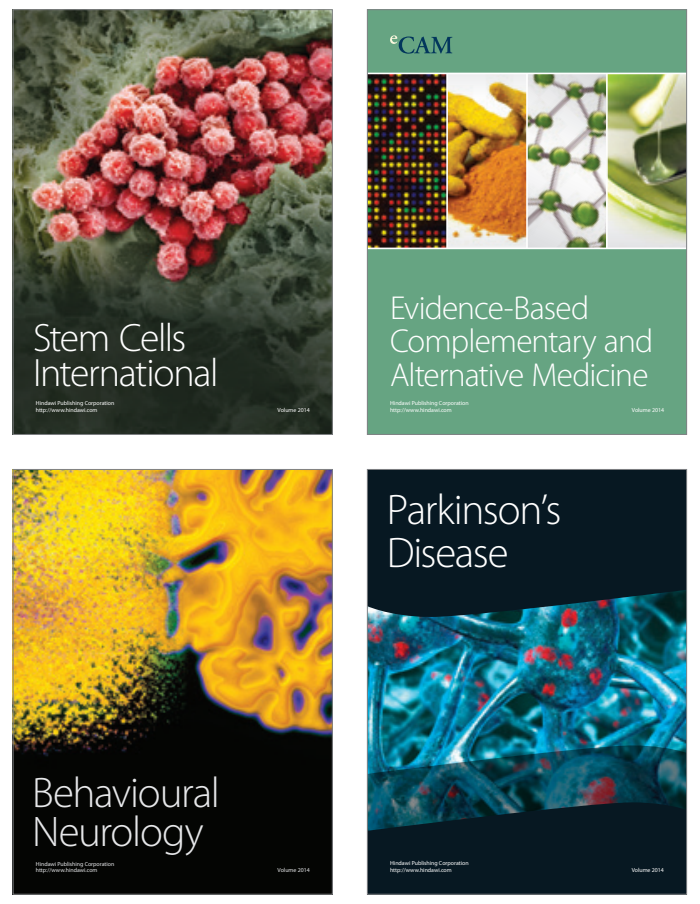
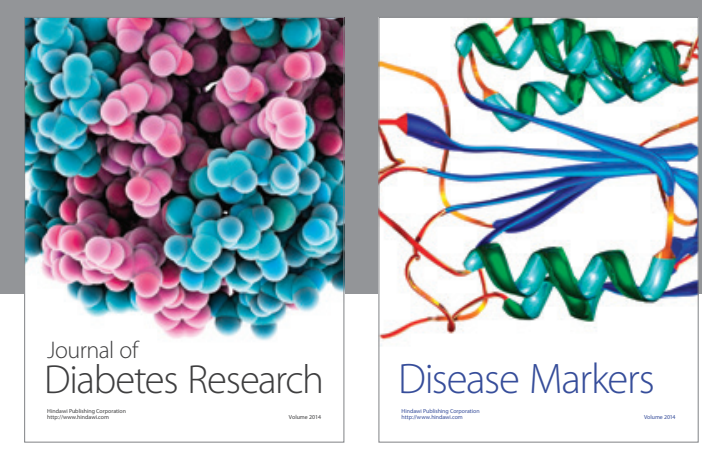

Disease Markers
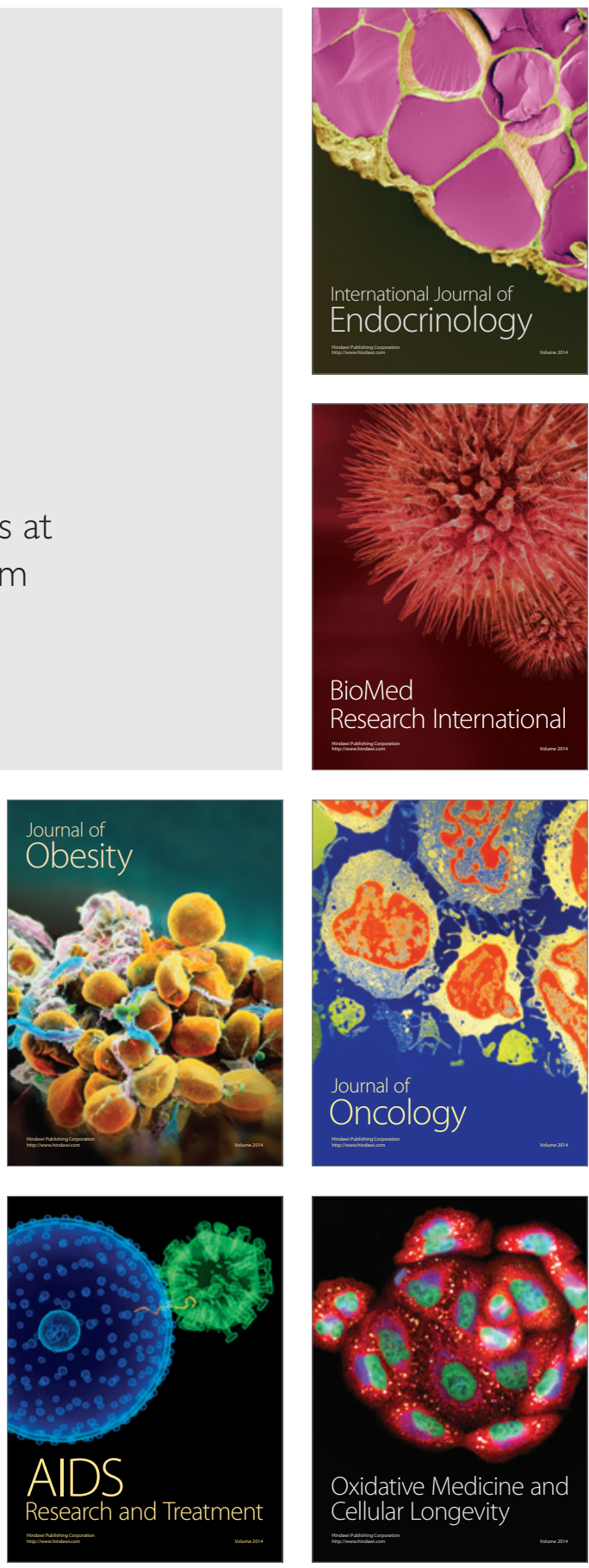